\title{
Apnea in Children Hospitalized With Bronchiolitis
}

WHAT'S KNOWN ON THIS SUBJECT: Apnea is a life-threatening complication of bronchiolitis and has been associated with younger age, prematurity, and a parental report of apnea. Apnea is classically attributed to the respiratory syncytial virus, but little is known about the role of other viruses.

WHAT THIS STUDY ADDS: Among hospitalized children, low or high respiratory rates or low oxygen saturation on presentation were associated with subsequent apnea in the hospital. Several bronchiolitis pathogens were associated with apnea, with similar apnea risk across the major viral pathogens.
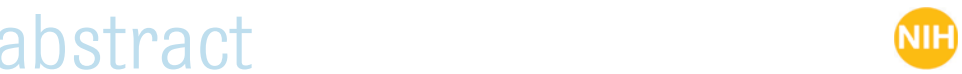

OBJECTIVE: To identify risk factors for inpatient apnea among children hospitalized with bronchiolitis.

METHODS: We enrolled 2207 children, aged $<2$ years, hospitalized with bronchiolitis at 16 sites during the winters of 2007 to 2010 . Nasopharyngeal aspirates (NPAs) were obtained on all subjects, and real-time polymerase chain reaction was used to test NPA samples for 16 viruses. Inpatient apnea was ascertained by daily chart review, with outcome data in 2156 children (98\%). Age was corrected for birth $<37$ weeks. Multivariable logistic regression was performed to identify independent risk factors for inpatient apnea.

RESULTS: Inpatient apnea was identified in 108 children (5\%, 95\% confidence interval $[\mathrm{CI}] 4 \%-6 \%)$. Statistically significant, independent predictors of inpatient apnea included: corrected ages of $<2$ weeks (odds ratio [OR] 9.67) and 2 to 8 weeks (OR 4.72), compared with age $\geq 6$ months; birth weight $<2.3 \mathrm{~kg}$ (5 pounds; OR 2.15), compared with $\geq 3.2$ kg (7 pounds); caretaker report of previous apnea during this bronchiolitis episode (OR 3.63); preadmission respiratory rates of $<30$ (OR 4.05), 30 to 39 (OR 2.35) and $>70$ (OR 2.26), compared with 40 to 49; and having a preadmission room air oxygen saturation $<90 \%$ (OR 1.60). Apnea risk was similar across the major viral pathogens.

CONCLUSIONS: In this prospective, multicenter study of children hospitalized with bronchiolitis, inpatient apnea was associated with younger corrected age, lower birth weight, history of apnea, and preadmission clinical factors including low or high respiratory rates and low room air oxygen saturation. Several bronchiolitis pathogens were associated with apnea, with similar apnea risk across the major viral pathogens. Pediatrics 2013;132:e1194-e1201
AUTHORS: Alan R. Schroeder, MD, a Jonathan M. Mansbach, MD, ${ }^{\mathrm{b}}$ Michelle Stevenson, MD, ${ }^{\mathrm{c}}$ Charles G.

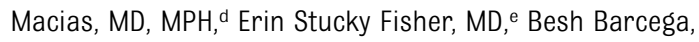
MD, ${ }^{f}$ Ashley F. Sullivan, MS, MPH,, 8 Janice A. Espinola, MPH, ${ }^{\circ}$ Pedro A. Piedra, MD, ${ }^{\mathrm{h}}$ and Carlos A. Camargo Jr, MD, DrPH\& ${ }^{a}$ Department of Pediatrics, Santa Clara Valley Medical Center, San Jose, California; 'Department of Medicine, Boston Children's Hospital, Harvard Medical School, Boston, Massachusetts; ${ }^{c}$ Department of Pediatrics, University of Louisville, Louisville, Kentucky; 'Department of Pediatrics, Section of Emergency Medicine, Texas Children's Hospital, Baylor College of Medicine, Houston, Texas; eDepartment of Pediatrics, Rady Children's Hospital, University of California, San Diego, San Diego, California; ${ }^{\text {DDepartment }}$ of Pediatrics, Loma Linda Medical Center, Loma Linda, California; gDepartment of Emergency Medicine, Massachusetts General Hospital, Harvard Medical School, Boston, Massachusetts; and ${ }^{h}$ Departments of Molecular Virology and Microbiology, and Pediatrics, Baylor College of Medicine, Houston, Texas

KEY WORDS

apnea, bronchiolitis, viral infections, infants, hospitalization

\section{ABBREVIATIONS}

$\mathrm{Cl}$-confidence interval

HRV—human rhinovirus

IQR-interquartile range

NPA —nasopharyngeal aspirate

$\mathrm{OR}$ - odds ratio

$\mathrm{PCR}$ - polymerase chain reaction

RR-respiratory rate

RSV—respiratory syncytial virus

Drs Schroeder and Mansbach conceptualized and designed the initial study, coordinated data collection at 1 of the sites, carried out the analysis and interpretation of data, and drafted the manuscript; Drs Stephenson, Macias, Fisher, and Barcega coordinated data collection at 1 of the sites and reviewed and revised the manuscript; Ms Sullivan was responsible for acquisition of data and reviewed and revised the manuscript; Ms Espinola was responsible for acquisition of data, analysis and interpretation of data, and drafting of the manuscript; Dr Piedra conceptualized and designed the initial study, coordinated data collection and virology testing, carried out the analysis and interpretation of data, and reviewed and revised the manuscript; Dr Camargo conceptualized and designed the initial study, coordinated data collection for all of the sites, carried out the analysis and interpretation of data, and drafted the manuscript; and all authors approved the final manuscript as submitted.

The content of this manuscript is solely the responsibility of the authors and does not necessarily represent the official views of the National Institute of Allergy and Infectious Diseases or the National Institutes of Health.

(Continued on last page) 
Apnea is a life-threatening complication of bronchiolitis, the leading cause of infant hospitalization in the United States. ${ }^{1,2}$ The incidence of apnea during bronchiolitis ranges across studies from $1 \%$ to $24 \%, 3-16$ a wide range that reflects the use of different definitions (eg, variable duration of apneic period), clinical settings (eg, outpatient vs inpatient), and inclusion/exclusion criteria (eg, age cutoffs, comorbidities, viral etiology).

Although two-thirds of children with severe bronchiolitis (ie, children requiring hospitalization) have respiratory syncytial virus (RSV), severe bronchiolitis is associated with multiple other viruses ${ }^{17}$ and even coinfections with multiple pathogens. ${ }^{17}$ Nonetheless previous apnea investigations have focused almost entirely on infants with RSV. $3,5-8,16,18,19$ Although evidence is sparse, apnea has been reported with parainfluenza virus, ${ }^{13}$ coronavirus, ${ }^{20}$ and human metapneumovirus. ${ }^{21}$

The current analysis is based on a large multicenter cohort of infants hospitalized with bronchiolitis and has the following aims: (1) to identify independent risk factors for the occurrence of apnea during the bronchiolitis hospitalization and (2) to compare virology results in infants with and without apnea.

\section{METHODS}

\section{Study Design}

We conducted a prospective, multicenter cohort study for 3 consecutive years during the 2007 to 2010 winter seasons, as part of the Multicenter Airway Research Collaboration, a program of the Emergency Medicine Network (www. emnet-usa.org). The number of participating sites varied from 13 to 16 each year. Each month from November 1 until March 31, site investigators across 12 US states used a standardized protocol to enroll a target number of consecutive patients from the inpatient wards and the ICU. We aimed to enroll $20 \%$ of our total sample from the ICU. To oversample children from the ICU, the ward and ICU enrollments were monitored separately. Once the site teams reached their target enrollment for each month, enrollment stopped until the beginning of the next month.

All patients were treated at the discretion of the treating physician. Inclusion criteria were an attending physician's diagnosis of bronchiolitis, age $<2$ years, and the ability of the caretaker to give informed consent. Patients were enrolled within 18 hours of admission. Exclusion criteria were transfer to a participating hospital $>48$ hours after the original admission time or previous enrollment (although data from the initial hospitalization for previously enrolled patients were still included). Patients with comorbidities were not excluded. The consent and data collection forms were translated into Spanish. The institutional review board at all participating hospitals approved the study.

\section{Data Collection}

Investigators conducted a structured interview with the children's caretakers that assessed patients' demographic characteristics, medical and environmental history, duration of symptoms, and details of the acute illness. The structured interview included the question, "Has [child] stopped breathing during this illness?" For the remainder of the article, we use the term "reported apnea" for this variable. Medical records were reviewed to obtain clinical data from the preadmission evaluation (clinic or emergency department) and the child's inpatient course, including respiratory rates (RR), daily respiratory rate trends, clinical assessment of degree of retractions, oxygen saturation, daily oxygen saturation trends, medical management, and disposition. These data were manually reviewed at the Emergency Medicine Network
Coordinating Center and site investigators were queried about missing data and discrepancies identified by these manual data checks.

To examine inpatient apnea among children admitted to the hospital with bronchiolitis, we identified all children who experienced apnea at any time during their hospitalization. Every day a child was in the hospital, site investigators examined the medical records of each participant for documentation of apnea. The site investigators completed the daily chart reviews by responding to the question: "Has patient experienced apnea?" Among the 2207 enrolled subjects, 2156 (98\%) had inpatient apnea status reported. Missing data were attributed to having no daily inpatient form available $(n=31$, $1.4 \%)$ or no response to the inpatient apnea question on any daily inpatient forms $(n=20,0.9 \%)$.

\section{Nasopharyngeal Aspirate \\ Collection and Virology Testing}

NPAs were performed by using a standardized protocol. Designated site personnel were trained by using a lecture, written instructions, and video. All of the sites used the same collection equipment (Medline Industries, Mundelein, IL) and collected $98 \%$ of the samples within 24 hours of a child's arrival on the medical ward or ICU. Once collected, the NPA sample was added to transport medium, placed on ice, and then stored at $-80^{\circ} \mathrm{C}$. Frozen samples were batch shipped overnight on dry ice to the central laboratory at Baylor College of Medicine, where they were stored at $-80^{\circ} \mathrm{C}$.

\section{Polymerase Chain Reaction Assay}

All polymerase chain reaction (PCR) assays were conducted as singleplex or duplex 2-step real-time PCR. Real-time reverse transcriptase-PCR was used for the detection of RNA and DNA respiratory viruses, which included RSV 
types $A$ and $B$; human rhinovirus (HRV); parainfluenza virus types 1,2 , and 3 ; influenza virus types A and B; 2009 novel H1N1; human metapneumovirus; coronaviruses NL-63, HKU1, 0C43, and 229E; enterovirus; and adenovirus. Mycoplasma pneumoniae and Bordetella pertussis were also sought by realtime PCR. Details of the primers and probes have been described elsewhere. ${ }^{22-24} \mathrm{All}$ real-time PCR assays were tested in duplicate and samples with incongruent values ( 1 well positive) were retested. To reduce carryover contamination, sample preparation, RNA/DNA extraction, cDNA, and amplification were performed in separate areas. All PCR runs had extraction and reagent positive and negative controls.

\section{Statistical Analyses}

All analyses were performed by using Stata 11.2 (Stata Corp, College Station, TX). Data are presented as proportions with $95 \%$ confidence intervals (Cls) and medians with interquartile ranges (IQR). To examine potential risk factors for apnea among patients hospitalized for bronchiolitis, we initially performed unadjusted analyses using $\chi^{2}$, Fisher's exact test, and Kruskall-Wallis test, as appropriate. All $P$ values were 2-tailed, with $P<.05$ considered statistically significant.

Multivariable logistic regression was conducted to evaluate independent predictors of inpatient apnea. Factors were tested for inclusion in the model if they were found to be associated with the outcome in unadjusted analyses $(P<.20)$ or were considered potentially clinically significant. To prevent the exclusion of children who were missing race data $(9 \%)$ and to minimize the number of included factors that were unassociated with inpatient apnea, race was dichotomized as white versus nonwhite/missing. Sensitivity analyses were performed using a 3-category version of the race variable (ie, white, nonwhite, and missing), but results did not materially differ compared with when using the dichotomized version (data not shown).

For all children born prematurely (gestational age $<37$ weeks), age was corrected by subtracting the number of weeks the child was premature from the chronologic age. More specifically, for a child with a gestational age $<37$ weeks, their corrected age was calculated by using the formula: chronological age $-(37-$ gestational age $)=$ corrected age. The final regression model accounts for potential clustering by site, with results reported as odds ratios (ORs) with $95 \%$ Cls.

\section{RESULTS}

Overall, the median age of the 2156 children in the analysis cohort was 4 months (IQR, 2-9 months), 59\% were boys, and $62 \%$ were white. Admission locations were as follows: ICU (16\%), step-down unit (3\%), ward (76\%), and observation unit (5\%).

During their inpatient stay, 108 infants (5\%; 95\% Cl, 4\%-6\%) had documented apnea. Of these cases, 56 (52\%) were managed at some point during the hospitalization in the ICU, and 30 (28\%) received mechanical ventilation (ie, continuous positive airway pressure and/or intubation). The majority (78\%) of infants with inpatient apnea were first observed to have apnea within the first 2 days of hospitalization. However, 3 patients (3\%) had apnea as late as 13 days into their hospital stay. Moreover, $86(80 \%)$ children had only 1 hospital day with recorded apnea, 13 (12\%) had apnea on 2 days, and 9 (8\%) had apnea on $>2$ days ( $\max =4$ days).

Unadjusted associations between demographic and clinical characteristics and inpatient apnea during the inpatient stay are presented in Tables 1 and 2. Infants with apnea were more likely to require ICU admission during the hospital stay (52\% vs $16 \%, P<$ $.001)$ and to have longer median length of stay (4 days vs 2 days, $P<.001$ ) compared with infants who did not have apnea. The multivariable logistic regression model for inpatient apnea is shown in Table 3. Independent risk factors included corrected age $<2$ weeks, birth weight $<2.3 \mathrm{~kg}$ (5 pounds), reported apnea, low $(<30$ and 30-39) and high $(>70)$ respiratory rates and oxygen saturation $<90 \%$ during the preadmission visit. The independent risk factor with the largest OR for apnea during the hospital stay was corrected age $<2$ weeks (0R 9.67, 95\% $\mathrm{Cl}$ 4.11-22.75). However, 17 (16\%) infants with apnea had a corrected age of $\geq 6$ months. Results from a sensitivity analysis that excluded these older children did not materially differ from results presented herein using all 2156 children (data not shown).

To examine whether premature birth $<37$ weeks and chronological age were independent predictors of apnea, we ran a second model that used these variables instead of the corrected age variable. In addition, due to the collinearity between prematurity and birth weight, birth weight was removed from this second model. In this model, young age ( $<1$ month: OR $5.16,95 \% \mathrm{Cl} 2.13-$ 11.49 ; $1-1.9$ months: OR $3.88,95 \% \mathrm{Cl}$ 1.95-7.71 compared with $\geq 6$ months) and prematurity (OR $2.44,95 \% \mathrm{Cl} 1.46-$ 4.09) were both independently associated with apnea, and other predictors did not differ materially from the model presented in Table 3.

Two hundred seventy-eight (13\%, 95\% Cl 12\%-14\%) children had parentreported apnea before admission during the current bronchiolitis episode. On multivariable analysis, previous apnea was an independent risk factor for inpatient apnea (OR 3.63, 95\% Cl 2.55-5.16). However, most children (59\%) with previous apnea did not experience apnea while hospitalized. 
TABLE 1 Demographic Characteristics and Medical History of Children With Bronchiolitis by Inpatient Apnea Status

\begin{tabular}{|c|c|c|c|c|}
\hline Characteristics & $n$ & $\begin{array}{l}\text { No Apnea } \\
(n=2048), \%\end{array}$ & $\begin{array}{c}\text { Apnea } \\
(n=108), \%\end{array}$ & $P$ \\
\hline \multicolumn{5}{|l|}{ History } \\
\hline Age, corrected for gestational age $<37$ wk & & & & $<.001$ \\
\hline$<2.0$ wk & 81 & 3 & 16 & \\
\hline $2.0-7.9 \mathrm{wk}$ & 531 & 23 & 46 & \\
\hline $2.0-5.9 \mathrm{mo}$ & 786 & 37 & 22 & \\
\hline$\geq 6.0 \mathrm{mo}$ & 758 & 36 & 16 & \\
\hline Gender & & & & .23 \\
\hline Male & 1278 & 60 & 54 & \\
\hline Female & 878 & 40 & 46 & \\
\hline Race & & & & .77 \\
\hline White & 1372 & 62 & 60 & \\
\hline Nonwhite or missing & 829 & 38 & 40 & \\
\hline Hispanic & 781 & 36 & 37 & .86 \\
\hline Birth wt & & & & .001 \\
\hline$<2.3 \mathrm{~kg}(5 \mathrm{lb})$ & 274 & 12 & 22 & \\
\hline $2.3-3.1 \mathrm{~kg}(5-6.9 \mathrm{lb})$ & 747 & 35 & 41 & \\
\hline$\geq 3.2 \mathrm{~kg}(7 \mathrm{lb})$ & 1110 & 53 & 36 & \\
\hline Any comorbidity & 454 & 21 & 19 & .55 \\
\hline Breast fed & 1303 & 61 & 56 & .28 \\
\hline Attends day care & 405 & 19 & 7 & .001 \\
\hline Maternal smoking during pregnancy & 325 & 15 & 20 & .19 \\
\hline Secondhand smoke exposure & 277 & 13 & 15 & .54 \\
\hline Reported apnea & 278 & 12 & 41 & $<.001$ \\
\hline Time difficulty breathing began before preadmission visit & & & & .53 \\
\hline None & 47 & 2 & 2 & \\
\hline$<24 \mathrm{~h}$ & 580 & 27 & 27 & \\
\hline $1-3 d$ & 913 & 43 & 37 & \\
\hline $4-7 d$ & 444 & 21 & 25 & \\
\hline$>7 d$ & 143 & 7 & 9 & \\
\hline \multicolumn{5}{|l|}{$\begin{array}{l}\text { Exposure to therapeutics within the week preceding the clinic } \\
\text { visit }\end{array}$} \\
\hline Bronchodilators & 816 & 39 & 23 & .001 \\
\hline Inhaled/nebulized steroids & 170 & 8 & 8 & .87 \\
\hline Systemic steroids & 232 & 11 & 10 & .90 \\
\hline Acetaminophen & 1151 & 56 & 38 & $<.001$ \\
\hline Antibiotics & 414 & 20 & 11 & .03 \\
\hline
\end{tabular}

Infants with and without inpatient apnea had similar viruses identified (Fig 1). For example, RSV was common among infants with and without apnea (78\% vs $72 \%, P=.16)$ as was HRV ( $24 \%$ vs $26 \%$, $P=.71$ ). The number of patients infected with viruses besides RSV and HRV was low when stratified by apnea status. However, adenovirus was isolated slightly less frequently in infants with apnea ( $3 \%$ vs $8 \%, P=.04$ ). For those viruses with multiple subtypes (RSV, influenza, parainfluenza, and coronavirus), there was no association between the viral subtype and apnea risk. Infants with viral coinfections (ie, $>1$ virus) had a similar frequency of apnea compared with infants who had only 1 virus identified ( $4 \%$ vs $6 \%, P=.08$ ).

Infants with apnea were significantly less likely to have been exposed to several therapeutic agents (antibiotics, acetaminophen, and bronchodilators) during the week before admission and were less likely to have attended day care (Table 1). However, on multivariable analysis, none of these associations were statistically significant.

\section{DISCUSSION}

In this prospective, multicenter study of apnea among infants hospitalized with bronchiolitis, we not only confirmed several previously reported risk factors for apnea (eg, young corrected age, low birth weight, and reported apnea) but also identified several novel preadmission risk factors including a low or high RR and a low room air oxygen saturation. Moreover, we found that multiple viruses were associated with apnea, with similar apnea risk across the major viral pathogens.

Inpatient apnea occurred in $5 \%$ of the hospitalized children in our bronchiolitis cohort. In one of the few other large, prospective investigations, Hall and colleagues found that apnea occurred in $1 \%$ of 561 children hospitalized with RSV infection. This study, however, included not only children aged $\leq 5$ years but also children without bronchiolitis. ${ }^{7}$ A more recent prospective, multicenter investigation of 1306 infants presenting to an emergency department with RSV infection (bronchiolitis, pneumonia, or apnea) reported apnea in $21(1.6 \%)$ children. ${ }^{8}$ The higher incidence in our data are most likely due to our population (severe bronchiolitis) and the fact that we oversampled children admitted to the ICU. Nonetheless, our reported incidence of $5 \%$ is lower than the $10 \%$ to $20 \%$ incidence rates based on populations of young ( $<6-12$ months) and/or premature infants hospitalized with RSV bronchiolitis. $5,6,14,15$ It is also possible that the administration of RSV immunoprophylaxis to vulnerable populations has led to a decrease in the overall in cidence of apnea.

We confirmed several risk factors for apnea including young corrected age, low birth weight, and reported apnea. In a retrospective study of 691 infants hospitalized with bronchiolitis, Willwerth and colleagues ${ }^{13}$ found that the 19 (3\%) children with apnea in their cohort all had $\geq 1$ of the following characteristics: age $<1$ month, born at $<37$ weeks gestation and $<48$ weeks postconception, and a witnessed apneic 
TABLE 2 Preadmission Clinical Presentation of Children With Bronchiolitis by Inpatient Apnea Status

\begin{tabular}{|c|c|c|c|c|}
\hline Clinical Characteristics & $n$ & $\begin{array}{c}\text { No Apnea } \\
(n=2048), \%\end{array}$ & $\begin{array}{c}\text { Apnea } \\
(n=108), \%\end{array}$ & $P$ \\
\hline Apnea (preadmission chart review) & 152 & 5 & 41 & $<.001$ \\
\hline Respiratory rate, median (IQR) & 2135 & $48(40-60)$ & $44(36-60)$ & .07 \\
\hline Respiratory rate & & & & .01 \\
\hline$<30$ & 121 & 5 & 12 & \\
\hline $30-39$ & 389 & 18 & 23 & \\
\hline $40-49$ & 655 & 31 & 22 & \\
\hline $50-59$ & 358 & 17 & 15 & \\
\hline $60-69$ & 394 & 19 & 14 & \\
\hline$\geq 70$ & 218 & 10 & 13 & \\
\hline Retractions & & & & .001 \\
\hline None & 472 & 21 & 33 & \\
\hline Mild & 901 & 42 & 29 & \\
\hline Moderate/severe & 633 & 30 & 26 & \\
\hline Missing & 150 & 7 & 12 & \\
\hline \multicolumn{5}{|l|}{ Oxygenation } \\
\hline Initial oxygen saturation, median (IQR) & 2109 & $96(93-98)$ & 97 (92-99) & 1.00 \\
\hline Initial oxygen saturation $<90 \%$ & 247 & 11 & 20 & .004 \\
\hline Lowest documented oxygen saturation, median (IQR) & 2119 & $93(89-96)$ & $92(85-96)$ & .03 \\
\hline Lowest documented oxygen saturation $<90 \%$ & 612 & 28 & 41 & .01 \\
\hline Oral intake & & & & .004 \\
\hline Adequate & 928 & 44 & 28 & \\
\hline Inadequate & 923 & 42 & 56 & \\
\hline Missing & 305 & 14 & 17 & \\
\hline IV line placed & 1218 & 56 & 73 & .001 \\
\hline Any laboratory tests & 1887 & 88 & 94 & .08 \\
\hline
\end{tabular}

IV, intravenous. event by either the parent or the emergency department clinician before inpatient admission. Birth weight was not included as a risk criterion. The positive predictive value was $7 \%$, reflecting the low overall incidence of apnea and the low specificity of these risk factors. Interestingly, none of the 672 children without apnea had 1 of these characteristics, resulting in a negative predictive value of $100 \%$.

One of the novel findings in our analysis was the U-shaped association between the preadmission RR and apnea. In other words, children with initial low RR $(<30$ and 30-39) or high RR ( $>70)$ had a higher risk of apnea than infants with an initial RR between 40 and 70 . To our knowledge, an association between initial RR and apnea has not been previously described, and there is no clear explanation for these novel findings. Although clinicians would consider children with bronchiolitis and a RR $>70$ as ill, a RR of $<30$ or 30-39 may be falsely reassuring. However, it is comforting to remember that all of the children in this cohort were hospitalized and therefore judged to be ill enough for hospitalization by the admitting clinician. Furthermore, these data require validation in a different study of children with bronchiolitis.

Infants with a preadmisison oxygen saturation $<90 \%$ were also at higher risk for apnea. Although the pathophysiology of apnea is unclear, Anas and colleagues ${ }^{3}$ found that 5 infants with apnea had a higher alveolararterial gradient than 27 infants without apnea (170 vs $45 \mathrm{~mm} \mathrm{Hg}, P<.01$ ). Although others have not found an association between oxygenation and apnea, ${ }^{6,13}$ we had a larger sample size and recorded oxygen saturation at both triage and throughout the preadmission visit. This methodology may have enabled us to identify this risk factor. Given that low pulse oximetry values are already used as a criterion 


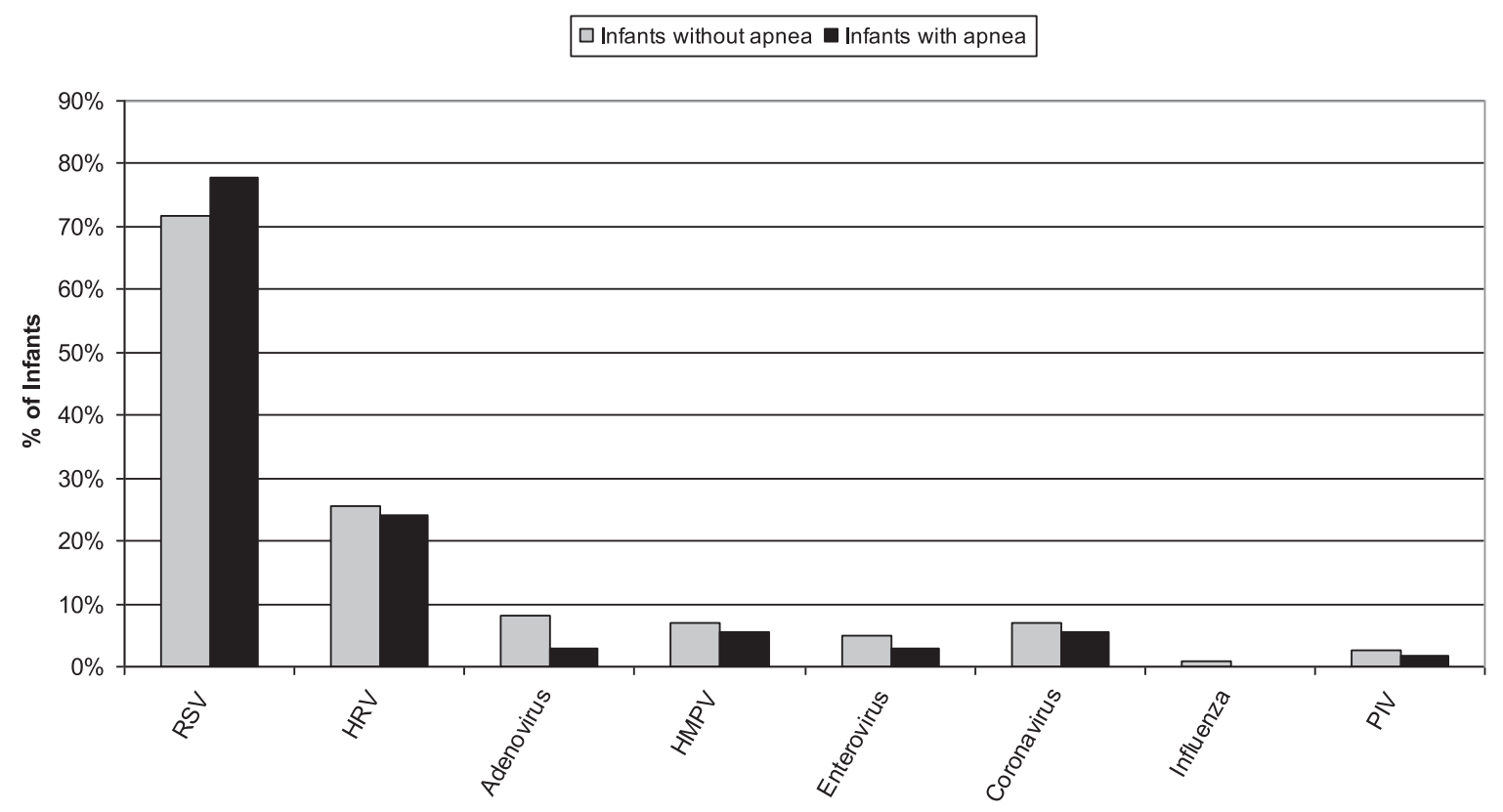

Viral Pathogen

FIGURE 1

Viral pathogens isolated in infants with and without apnea. HMPV, human metapneumovirus; PIV, parainfluenza virus.

for hospitalization and supplemental oxygen, ${ }^{22,23}$ this finding may not affect clinical practice.

Our virology results demonstrate that many viruses are associated with inpatient apnea during the bronchiolitis hospitalization. Multiple previous investigations of apnea associated with viral infections have focused exclusively on RSV, and several sources have perpetuated the notion that RSV specifically should heighten concerns of apnea in comparison with other viruses.5,24 However, according to our data, the risk of apnea does not significantly differ in infants with RSV and non-RSV bronchiolitis. These data suggest that using RSV status to drive admission decisions and admission locations (eg, ward, step-down unit, ICU) due to apnea concerns may be misguided. Supporting the lack of an association between virology and apnea is the finding that viral etiology was not linked with the acute severity of bronchiolitis (as measured by initial admission to ICU or the use of mechanical ventilation) in this same cohort. How- ever, it should be noted that we did find an association between viral etiology and hospital length of stay. ${ }^{17}$

Exposure to various therapeutic agents (antibiotics, acetaminophen, and bronchodilators) during the week before admission appeared to have a "protective" association against apnea in unadjusted analyses. On multivariable analysis, however, none of these medications remained statistically significant, thereby confirming the presence of $\geq 1$ confounding factors. Even though a recent study of 42 infants with apnea concluded that acetaminophen was protective against apnea, ${ }^{25}$ we caution against using acetaminophen for this purpose; based on a much larger sample, our data do not support this inference.

The time course of apnea in bronchiolitis is not well understood. In previous studies, apnea has been described to occur early in the course of RSV infection. 3,26 Our results challenge this notion. Approximately one-third of the infants with apnea in our study began having "difficulty breathing" $\geq 4$ days before the preadmission visit. Furthermore, the time from the beginning of the "difficulty breathing" to the preadmission visit was not different between children with and without apnea. Therefore, using the duration of symptoms to predict future risk of apnea or need for hospitalization may be problematic.

Our study has several potential limitations. Although it was a large, prospective study that required daily recording of the presence of apnea, the reported incidence of apnea (5\%) may be biased by several factors. First, sicker patients were oversampled because we aimed to enroll $20 \%$ of our sample from the ICU. Second, subjects were considered to have apnea if there was documentation in the chart that apnea had occurred, so some infants may have been included who did not meet strict criteria for apnea (eg, cessation of breathing for at least 20 seconds ${ }^{4,10}$ ). Alternatively, apnea may have been more challenging to detect in intubated patients leading to underreporting in this population. Last, 
bronchiolitis is a clinical diagnosis. ${ }^{22}$ As a result, the site teams may have included children who did not have bronchiolitis or missed children who presented with apnea ${ }^{22}$ and were diagnosed with an acute life-threatening event ${ }^{27}$ or "apnea" instead of bronchiolitis. Nonetheless, this is the largest prospective study of apnea in children with bronchiolitis and included data from 16 hospitals across the United States.

\section{CONCLUSIONS}

In these prospective, multiyear, multicenter data, we found several historical and clinical factors associated with apnea among children hospitalized with bronchiolitis. The association between low respiratory rates and apnea provides cautionary data to practitioners feeling reassured by lower RR. Moreover, the finding that multiple viruses are associated with apnea, with similar apnea risk across the major viral pathogens, suggests possible changes in clinicians' practice. Our findings do not support the practice of using virology results to drive management decisions involving infants with apnea or the potential for apnea.

\section{ACKNOWLEDGMENTS}

The Principal Investigators at the 16 Participating Sites were as follows: Besh Barcega, MD, Loma Linda University Children's Hospital (Loma Linda, CA); John Cheng, MD and Carlos Delgado, MD, Children's Healthcare of Atlanta at Egleston (Atlanta, GA); Dorothy Damore, MD and Nikhil Shah, MD, New York Presbyterian Hospital (New York, NY); Haitham Haddad, MD, Rainbow Babies \& Children's Hospital (Cleveland, $\mathrm{OH}$ ); Paul Hain, MD and Mark Riederer, MD, Monroe Carell Jr. Children's Hospital at Vanderbilt (Nashville, TN); Frank LoVecchio, D0, Maricopa Medical Center
(Phoenix, AZ); Charles Macias, MD, MPH, Texas Children's Hospital (Houston, TX); Jonathan Mansbach, MD, Boston Children's Hospital (Boston, MA); Eugene Mowad, MD, Akron Children's Hospital (Akron, $\mathrm{OH}$ ); Brian Pate, MD, Children's Mercy Hospital \& Clinics (Kansas City, M0); M. Jason Sanders, MD, Children's Memorial Hermann Hospital (Houston, TX); Alan Schroeder, MD, Santa Clara Valley Medical Center (San Jose, CA); Michelle Stevenson, MD, MS Kosair Children's Hospital (Louisville, KY); Erin Stucky Fisher, MD, Rady Children's Hospital (San Diego, CA); Stephen Teach, MD, MPH, Children's National Medical Center (Washington, DC); and Lisa Zaoutis, MD, Children's Hospital of Philadelphia (Philadelphia, PA).

We thank the Multicenter Airway Research Collaboration-30 investigators for their ongoing dedication to bronchiolitis research.

\section{REFERENCES}

1. Shay DK, Holman RC, Newman RD, Liu LL, Stout JW, Anderson LJ. Bronchiolitisassociated hospitalizations among US children, 1980-1996. JAMA. 1999;282(15): 1440-1446

2. Yorita KL, Holman RC, Sejvar JJ, Steiner CA, Schonberger LB. Infectious disease hospitalizations among infants in the United States. Pediatrics. 2008;121(2):244-252

3. Anas N, Boettrich C, Hall CB, Brooks JG. The association of apnea and respiratory syncytial virus infection in infants. $J$ Pediatr. 1982;101(1):65-68

4. Brandenburg AH, Jeannet PY, Steensel-Moll $H A$, et al. Local variability in respiratory syncytial virus disease severity. Arch Dis Child. 1997;77(5):410-414

5. Bruhn FW, Mokrohisky ST, McIntosh K. Apnea associated with respiratory syncytial virus infection in young infants. J Pediatr. 1977;90(3):382-386

6. Church NR, Anas NG, Hall CB, Brooks JG. Respiratory syncytial virus-related apnea in infants. Demographics and outcome. Am J Dis Child. 1984;138(3):247-250
7. Hall CB, Weinberg GA, Iwane MK, et al. The burden of respiratory syncytial virus infection in young children. $N$ Engl $J$ Med. 2009;360(6):588-598

8. Jafri HS, Wu X, Makari D, Henrickson KJ. Distribution of respiratory syncytial virus subtypes $A$ and $B$ among infants presenting to the emergency department with lower respiratory tract infection or apnea. Pediatr Infect Dis J. 2013;32(4):335-340

9. Kneyber MC, Brandenburg AH, de Groot R, et al. Risk factors for respiratory syncytial virus associated apnoea. Eur J Pediatr. 1998; 157(4):331-335

10. Simon A, Ammann RA, Wilkesmann A, et al; DSM RSV Paed Study Group. Respiratory syncytial virus infection in 406 hospitalized premature infants: results from a prospective German multicentre database. Eur J Pediatr. 2007;166(12):1273-1283

11. Wahab AA, Dawod ST, Raman HM. Clinical characteristics of respiratory syncytial virus infection in hospitalized healthy infants and young children in Qatar. $J$ Trop Pediatr. 2001;47 (6):363-366
12. Wang EE, Law BJ, Boucher FD, et al. Pediatric Investigators Collaborative Network on Infections in Canada (PICNIC) study of admission and management variation in patients hospitalized with respiratory syncytial viral lower respiratory tract infection. J Pediatr. 1996;129(3):390-395

13. Willwerth BM, Harper MB, Greenes DS. Identifying hospitalized infants who have bronchiolitis and are at high risk for apnea. Ann Emerg Med. 2006;48(4):441-447

14. Colditz PB, Henry RL, DeSilva LM. Apnoea and bronchiolitis due to respiratory syncytial virus. Aust Paediatr J. 1982;18(1):53-54

15. McConnochie KM, Hall CB, Walsh EE, Roghmann $\mathrm{KJ}$. Variation in severity of respiratory syncytial virus infections with subtype. $J$ Pediatr. 1990;117(1 pt 1):52-62

16. Ralston S, Hill V. Incidence of apnea in infants hospitalized with respiratory syncytial virus bronchiolitis: a systematic review. J Pediatr. 2009;155(5):728-733

17. Mansbach JM, Piedra PA, Teach SJ, et al; MARC-30 Investigators. Prospective multicenter study of viral etiology and hospital 
length of stay in children with severe bronchiolitis. Arch Pediatr Adolesc Med. 2012;166(8):700-706

18. Arms JL, Ortega H, Reid S. Chronological and clinical characteristics of apnea associated with respiratory syncytial virus infection: a retrospective case series. Clin Pediatr (Phila). 2008;47(9):953-958

19. Schiller 0, Levy I, Pollak U, Kadmon G, Nahum E, Schonfeld T. Central apnoeas in infants with bronchiolitis admitted to the paediatric intensive care unit. Acta Paediatr. 2011;100(2):216-219

20. Simon A, Völz $S$, Höfling $K$, et al. Acute life threatening event (ALTE) in an infant with human coronavirus HCoV-229E infection. Pediatr Pulmonol. 2007;42(4):393-396
21. Jofré ML, Luchsinger FV, Zepeda FG, Rojas CA, Munoz AA. Apnea as a presenting symptom in human metapneumovirus infection [in Spanish]. Rev Chilena Infectol. 2007;24(4):313-318

22. American Academy of Pediatrics Subcommittee on Diagnosis and Management of Bronchiolitis. Diagnosis and management of bronchiolitis. Pediatrics. 2006;118(4): 1774-1793

23. Mallory MD, Shay DK, Garrett J, Bordley WC. Bronchiolitis management preferences and the influence of pulse oximetry and respiratory rate on the decision to admit. Pediatrics. 2003;111(1). Available at: www.pediatrics.org/cgi/content/full/ $111 / 1 / \mathrm{e} 45$
24. Zorc JJ, Hall CB. Bronchiolitis: recent evidence on diagnosis and management. $P e-$ diatrics. 2010;125(2):342-349

25. Walsh P, Shanholtzer L, Loewen M, Trinh K, McEnulty B, Rothenberg SJ. A matched case control study with propensity score balancing examining the protective effect of paracetamol against parentally reported apnoea in infants. Resuscitation. 2012;83(4):440-446

26. Rayyan M, Naulaers G, Daniels H, Allegaert K, Debeer A, Devlieger $\mathrm{H}$. Characteristics of respiratory syncytial virus-related apnoea in three infants. Acta Paediatr. 2004;93(6):847-849

27. Al-Kindy HA, Gelinas JF, Hatzakis G, Cote A. Risk factors for extreme events in infants hospitalized for apparent life-threatening events. $J$ Pediatr. 2009;154(3):332-337, 337.e1-2

(Continued from first page)

www.pediatrics.org/cgi/doi/10.1542/peds.2013-1501

doi:10.1542/peds.2013-1501

Accepted for publication Aug 22, 2013

Address correspondence to Alan Schroeder, MD, Department of Pediatrics, Santa Clara Valley Medical Center, 751 S Bascom Ave, San Jose, CA 95128. E-mail: Alan. Schroeder@hhs.sccgov.org

PEDIATRICS (ISSN Numbers: Print, 0031-4005; Online, 1098-4275).

Copyright (C) 2013 by the American Academy of Pediatrics

FINANCIAL DISCLOSURE: The authors have indicated they have no financial relationships relevant to this article to disclose

FUNDING: Supported by grants U01 Al-67693 and K23 Al-77801 from the National Institutes of Health (Bethesda, MD). Funded by the National Institutes of Health $(\mathrm{NIH})$

POTENTIAL CONFLICT OF INTEREST: The authors have indicated they have no potential conflicts of interest to disclose. 